\title{
US plan for routine HIV testing alarms privacy advocates
}

In a sweeping revision of HIV guidelines, US federal officials are planning to recommend that people be routinely tested for HIV infection. But AIDS and civil liberties advocates are opposing the plans, saying it could lead to testing without proper consent and violate individuals' privacy.

Nearly $25 \%$ of an estimated 1 million people in the US don't know they are infected with HIV.The US Centers for Disease Control and Prevention (CDC) estimates that these individuals may be responsible for more than half of the 40,000 new infections each year. By routinely testing everyone between the ages of 13 and 64, the agency hopes to boost the number of those diagnosed.

The agency released a preliminary version of the guidelines in March. Testing will remain voluntary, but the guidelines propose eliminating pretest counseling and written consent required by many local and state laws.

If that policy is enforced, infected individuals might not receive the counseling and treatment they need, say AIDS activists.

"We really support the goal of getting more people tested," says Rose Saxe, a staff attorney at the American Civil Liberties Union's national

Smoking rates in some countries such as the US have steadily declined over
AIDS Project in New York. "But it has to be done in a way that protects privacy, gives informed consent to medical care and ensures adequate counseling so that people can be prepared if they're HIV positive."

Washington, DC has already incorporated many of the CDC's proposed recommendations into its new HIV/AIDS campaign, launched 27 June, and offers tests to everyone ages 14 to 84 .

"It's time to integrate HIV testing into routine health care," says Marsha Martin, senior deputy director of the DC Administration for HIV Policy and Programs. Martin says local programs and free clinics can handle the potential influx of people who test positive and need counseling and treatment.

Opponents question whether that support exists nationwide, however, especially given long waiting lists for state drug programs. "It is one thing to have a policy on routine testing; it is another to make sure resources are in place," says Frenk Guni of the advocacy group National Association of People with AIDS.

Getting the tests paid for could prove challenging, for instance. Publicly funded health services can't cover testing without federal authorization, and insurance companies haven't said whether they'll cover it, says Guni.

Chances are they won't, says Susan Pisano, a spokeswoman for America's Health Insurance Plans, a trade association representing 1,300 companies. Health insurers generally take their cue from the US Preventive Services Task Force, an independent panel of experts in primary care and prevention. The task force found in July 2005 that there is inadequate evidence to recommend for or against routine testing.

Elsewhere in the US, activists and legislators have managed to slow down the efforts to loosen informed consent requirements. The San Francisco Board of Supervisors on 21 June passed an ordinance asking the city to keep written informed consent for testing, in line with state law (Nat. Med. 12, 378; 2006).

The CDC declined to comment on opponents' concerns, but a spokeswoman says the agency has received public comments and is currently revising the guidelines for publication in late summer.

Alisa Opar, New York

\section{Anti-tobacco efforts going up in smoke} the past few decades, but tobacco use continues to climb in Asia, Latin America and Africa. In Vietnam for example, smokers spend nearly four times as much on tobacco as they do on education and twice as much as on healthcare. Tobacco-related deaths will claim about $10 \%$ of the current population and the number of deaths each year is expected to double to 10 million by 2025, according to The Tobacco Atlas, published by the American Cancer Society in July.

Since the first tobacco atlas was released in 2002, 133 countries have ratified the World Health Organization Framework Convention on Tobacco Control, which calls for protection against secondhand smoke, restrictions on advertising and other measures. Despite that, an estimated 1 billion men and 250 million women worldwide regularly light up.

Charlotte Schubert, Washington, DC
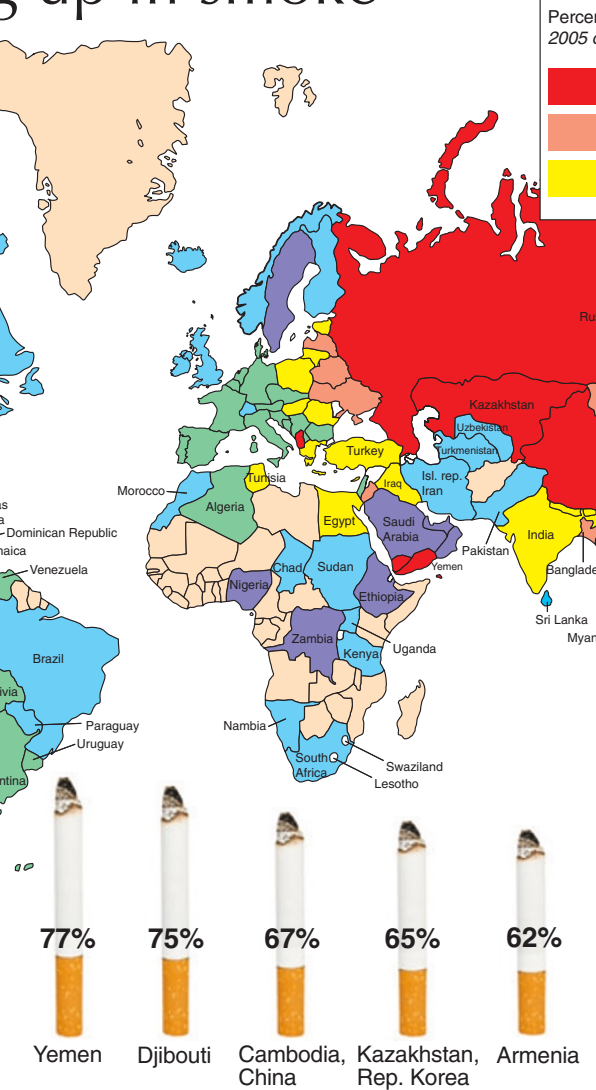

\section{Smoking prevalence in men}

Percentage of males who smoke cigarettes 2005 or latest available data \begin{tabular}{lll} 
& \\
\hline
\end{tabular} 50\%-59.9\% $\quad 20 \%-29.9 \%$ $40 \%-49.9 \% \quad$ Below $20 \%$
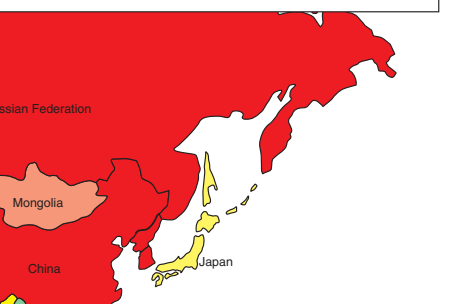
造 .
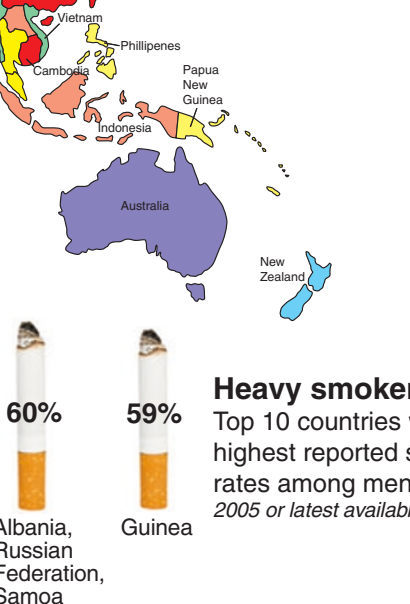

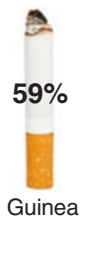

Heavy smokers

Top 10 countries with highest reported smoking

rates among men 2005 or latest available data 